\title{
Circadian Rhythm, Sleep Quality, and Health-Related Quality of Life in Korean Middle Adults
}

\author{
Daeyoung Kim ${ }^{1}$, Hee Jin Chang ${ }^{1}$, Wankiun Lee ${ }^{1}$, Hoseong Seo ${ }^{1}$, \\ Kwang Ik Yang ${ }^{2}$, Min Kyung Chu ${ }^{3}$, Chang-Ho Yun ${ }^{4}$ \\ ${ }^{1}$ Department of Neurology, Chungnam National University Hospital, Chungnam National University College of Medicine, Daejeon, \\ ${ }^{2}$ Sleep Disorder Center, Department of Neurology, Soonchunhyang University Cheonan Hospital, Soonchunhyang University College of Medicine, \\ Cheonan, \\ ${ }^{3}$ Department of Neurology, Severance Hospital, Yonsei University College of Medicine, Seoul, \\ ${ }^{4}$ Department of Neurology, Bundang Clinical Neuroscience Institute, Seoul National University Bundang Hospital, Seongnam, Korea
}

\author{
대한민국 중기 성인에서 일주기리듬, 수면의 질, 그리고 건강 관련 삶의 질 \\ 김대영 ${ }^{1}$, 장희진 ${ }^{1}$, 이완균 ${ }^{1}$, 서호성 ${ }^{1}$, 양광익 ${ }^{2}$, 주민경 $^{3}$, 윤창호 ${ }^{4}$ \\ 충남대학교 의과대학 충남대학교병원 신경과, ${ }^{1}$ 순천향대학교 천안병원 신경과, 수면장애센터, ${ }^{2}$ \\ 연세대학교 의과대학 세브란스병원 신경과, ${ }^{3}$ 분당서울대학교병원 뇌신경병원 신경과 ${ }^{4}$
}

\section{Received April 5, 2020 \\ Revised April 14, 2020 \\ Accepted April 22, 2020}

Address for correspondence

Chang-Ho Yun, MD, PhD

Department of Neurology,

Bundang Clinical

Neuroscience Institute,

Seoul National University

Bundang Hospital,

82 Gumi-ro 173beon-gil,

Bundang-gu, Seongnam 13620,

Korea

Tel: +82-31-787-7469

Fax: +82-31-787-4059

E-mail: ych333@gmail.com

Daeyoung Kim, MD, PhD

Department of Neurology,

Chungnam National University

Hospital, Chungnam National

University College of Medicine,

282 Munhwa-ro, Jung-gu,

Daejeon 35015, Korea

Tel: $+82-42-280-7934$

Fax: +82-42-252-8654

E-mail: bigbread.kim@gmail.com
Objectives: The aim of this study is to evaluate relationship of health-related quality of life (HRQoL) with chronotype along with quality and quantity of sleep in Korean middle adults. Methods: Data was derived from the nationwide, cross-sectional study on sleep surveyed 2,501 representative adult Koreans. We collected data from 1,435 participants aged $\geq 35$ years and $<65$ years to represent Korean middle adults. The Chronotype Questionnaire was used to assess phase and distinctiveness of the circadian rhythm. The Pittsburgh Sleep Quality Index (PSQI) was used to assess sleep quality. Quantity of sleep was investigated by questions regarding sleep habits during workdays and free days. EuroQol-5D 3-level version was used to measure HRQoL. Results: On univariable analyses, eveningness is associated with younger age ( $47.7 \pm 8.2$ vs. $51.3 \pm 8.1$ years, $p<0.001)$, and higher PSQI total score $(4.3 \pm 2.7$ vs. $3.6 \pm 2.2, p<0.001)$ compared with morningness. Strong distinctiveness also associated with higher PSQI total score $(4.2 \pm 2.3$ vs. $3.6 \pm 2.5, p<$ 0.001 ) compared with weak distinctiveness. Age was not different between the two groups of distinctiveness. On multivariable analyses, strong distinctiveness is an independent factor predicting impairment of pain/ discomfort [odd ratio (OR) 1.589, 95\% confidence interval (CI) 1.182-2.130] and depression/anxiety (OR 1.412, 95\% CI 1.003-1.987). Poor sleep quality was the most powerful independent factor predicting impairments in all five domains of the HRQoL. Conclusions: Sleep quality is an important factor independently related to the HRQoL. Among chronotype variables, only distinctiveness has an independent relation with the HRQoL.

J Sleep Med 2020;17(1):66-72
서 론

사람은 제각각 자신에게 편한 잠드는 시간과 일어나는 시

This is an Open Access article distributed under the terms of the Creative Commons Attribution Non-Commercial License (https://creativecommons.org/licenses/by-nc/4.0) which permits unrestricted non-commercial use, distribution, and reproduction in any medium, provided the original work is properly cited.
간이 있고, 이 시간에 따라 하루 중 최상의 신체와 정신 활동 이 가능한 시간이 다르다. 이 하루주기의 시간적 선호도는 개 인에서는 비교적 일정하게 나타나며, 이를 일주기유형(chronotype)이라 한다. 일주기유형은 아침형, 중간형, 저녁형의 세 가지로 분류한다. ${ }^{1}$ 성인의 약 $60 \%$ 는 중간형이고 나머지 $40 \%$ 는 아침형 혹은 저녁형의 극단형이며, 극단형들 간의 시 
차는 2 시간 내지 12 시간으로 알려져 있다. ${ }^{1}$ 아침형 인간과 저 녁형 인간은 생리, 심리, 행동, 건강, 인격 등 다양한 측면에 서 차이를 보인다. ${ }^{2,3}$

일주기유형은 연령에 따라 뚜렷한 변화를 보인다. 십대에 들어서면서 저녁형의 성향을 보이기 시작하여 20세를 전후 로 저녁형의 최고조를 보이고, 이후 연령이 증가하면서 점진 적으로 아침형으로 변하는 성향을 보인다. ${ }^{4-6}$ 65세를 넘어서 부터는 일주기유형의 개인별 차이가 커진다. ${ }^{7}$ 성별에 따라서 도 일주기유형은 차이를 보이는데, 일반적으로 남성이 좀 더 저녁형 성향을 보인다. ${ }^{8}$ 여성은 30 세에 이르기까지는 남성보 다 아침형 성향을 보이지만 30세를 넘어서부터는 남성과의 차이가 덜해지며, 폐경 이후로는 남성보다 저녁형 성향을 보 인다. ${ }^{9}$ 성인기의 분류 기준은 분명히 정해져 있지는 않으나 30 대 중반까지의 초기 성인기, 30 대 중반부터 60 대 중반까지 의 중기 성인기, 그리고 60 대 중반 이후의 후기 성인기 혹은 노년기로 나눌 수 있다. 중기 성인기는 비교적 일주기유형의 안정적인 변화와 남녀 간의 적은 차이를 보이는 시기이다.

수면의 질이 삶의 질과 연관된다는 것은 잘 알려져 있다. ${ }^{10-12}$ 저녁형 일주기유형 또한 삶의 질 저하와 연관되는 것으로 보 고되고 있으나 그 정도는 수면의 질보다는 덜하고 다양하며, 수면 부족, 연령, 성별 등 다양한 요인들의 영향을 받는 것으 로 보인다. ${ }^{13-15}$ 본 연구는 일주기유형이 비교적 안정적인 중 기 성인기의 한국인에서 수면의 질과 양, 그리고 일주기유형 이 건강 관련 삶의 질에 미치는 영향을 조사하기 위한 목적 으로 시행되었다.

\section{방 법}

본 연구는 제주도를 제외한 대한민국 전체 19세 이상 성인 인구를 대상으로 한 단면 연구의 일부로서, 전체 대상자 중 35 세 이상이며 65 세 미만인 중기 성인을 대상으로 분석을 시 행하였다. 설문 조사는 한국갤럽조사연구소(서울, 대한민국) 에서 시행하였고, 훈련받은 면접자가 대상자 조건에 적합한 사람에게 조사의 목적을 설명하고 고지에 입각한 동의를 얻 은 후 구조화된 설문을 사용하여 대면조사를 하였다. 조사 기간은 2018년 10월부터 동년 11월까지였다. 본 연구는 충남 대학교병원의 기관윤리심의위원회의 승인(IRB No. CNUH 2018-04-005-002)하에 진행되었다.

\section{대상자 선정}

제주도를 제외한 대한민국은 지리학적으로 15 개의 광역지 방자치단체(특별시, 광역시, 특별자치시, 도)로 나뉘어 있으 며, 각각의 광역지방자치단체는 다시 75 개의 시와 82 개의
군, 69 개 구의 기초지방자치단체로 나뉜다. 2018년 대한민국 의 인구는 $51,817,851$ 명으로 추산되며, 이 중 19 세 이상의 인 구는 42,394,045명으로 추산된다. ${ }^{16}$

각 행정구역의 인구 구조에 비례하여 대상자를 선정하기 위해 2단계 체계적 무작위 추출 기법을 사용하였다. 첫 단계 로, 15 개의 광역지방자치단체를 일차 선정 단위로 지정하고 인구 분포에 따라 표본 수를 배정하였다. 두 번째 단계로 각 각의 일차 선정 단위를 대표하는 총 60 개의 대표적인 기초자 치단체를 선정한 후 연령, 성별을 고려하여 각각의 기초자치 단체에서 총 2,501명의 목표 표본 수를 할당하였다.

\section{일주기유형에 대한 설문}

일주기유형의 측정은 Ogińnka의 Chronotype Questionnaire $(\mathrm{ChQ})$ 를 저자 $(\mathrm{DK}, \mathrm{CHY})$ 가 한글로 번역하여 사용하였 다. ${ }^{17} \mathrm{ChQ}$ 는 일주기유형의 두 가지 측면을 측정할 수 있는 특 성이 있다. 첫 번째 측면은 주관적 위상, 즉 아침-저녁 선호 도이며 morningness-eveningness(ME) 척도로 불리는 8개의 문항으로 이루어진다. "내가 가장 잘 생각한다고 느끼는 때는 아침이다(I feel I can think the best in the morning)"와 같은 문장에 “예”, "?”(때에 따라 달라 답하기 어려움), "아니오”의 세 가지로 응답하며, 점수는 문항에 따라 각각 $1,3,5$ 점 혹은 $5,3,1$ 점이다. 총점은 8점 내지 40점이며, 점수가 높을수록 저녁형에 가까움을 의미한다. 두 번째 측면은 일주기리듬의 주관적 진폭(amplitude) 혹은 분명성(distinctiveness, DI)이 며 DI 척도로 불리는 6개 문항이다. "나는 낮이든 밤이든 똑 같이 편히 일할 수 있다(I can work equally easily in the day as in the night)"와 같은 문항들이며, 선택할 수 있는 응답과 점수는 $\mathrm{ME}$ 척도와 동일하다. 총점은 6점 내지 30점이고 점 수가 높을수록 일주기리듬의 분명성이 더 강함을 의미한다. 일주기리듬의 분명성이 강할수록 자신이 선호하는 리듬과 다른 시간대에 활동하는 것에 어려움을 느낀다. 19세 이상 성인 응답자 전체를 대상으로 25 백분위수와 75 백분위수의 $\mathrm{ME}$ 척도 점수를 구하였으며, 25 백분위수 점수 미만일 경우 아침형, 75 백분위수 점수 초과의 경우 저녁형, 나머지를 중 간형으로 정의하였다. DI 척도는 19세 이상 성인 응답자 전 체의 중간값을 기준으로 하여 약한 일주기리듬 분명성과 강 한 일주기리듬 분명성으로 분류하였다.

\section{수면의 질에 대한 설문}

수면의 질은 피츠버그 수면의 질 지수(Pittsburgh Sleep Quality Index, PSQI)를 사용하여 조사하였다. ${ }^{18}$ 타당화된 한 국어판을 사용하였으며, 총점이 8.5점 이상일 경우 수면의 질이 불량한 것으로 간주하였다. ${ }^{19}$ 


\section{수면의 양에 대한 설문}

일하는 날과 쉬는 날 각각에 대하여 잠자리에 눕는 시각, 실제 잠을 잘 준비가 되는 시각, 잘 준비가 된 이후 잠드는 데까지 걸리는 시간, 깨어나는 시각, 잠자리에서 일어나는 시각을 조사하였고, 한 주 중 일하는 날수와 쉬는 날수를 조 사하였다. 실제 잠을 잘 준비가 되는 시각부터 깨어나는 시 각까지의 시간에서 잠드는 데까지 걸리는 시간을 빼서 수면 시간을 계산하였다. 주간 평균 수면시간은 다음과 같이 계산 하였다:

주간 평균 수면시간=[(일하는 날 수면시간 $\times$ 일하는 날 수)+(쉬는 날 수면시간 $\times$ 쉬는 날수)]/7

\section{건강 관련 삶의 질에 대한 설문}

건강 관련 삶의 질은 EuroQol-5D 3-level version(EQ$5 \mathrm{D}-3 \mathrm{~L})$ 을 이용하여 조사하였다. ${ }^{20} \mathrm{EQ}-5 \mathrm{D}-3 \mathrm{~L}$ 은 운동능력 (mobility), 자기 관리(self-care), 일상활동(usual activity), 통 증/불편감(pain/discomfort), 그리고 불안/우울(anxiety/depression)의 5 개 영역에 대한 현 상태를 3 개 수준(지장 없음, 다소 지장이 있음, 극단적인 지장이 있음) 중 하나로 응답하 는 자가설문이다. 각각의 질문에 대한 응답이 다소 혹은 극 단적인 지장이 있음일 경우 해당 영역에서의 장애가 있는 것 으로 간주하였다. 또한 Lee 등이 한국인을 대상으로 구해낸 질 가중치(quality weight)를 적용하여 총점을 계산하였다. ${ }^{21}$ 점수 범위는 -0.171 부터 0.950 까지이며, 점수가 낮을수록 전 반적으로 낮은 삶의 질을 시사한다.

\section{통계 분석}

성별 간 연속형 변수의 비교 검증에는 독립 $\mathrm{t}$-검증을 사용 하였으며, 범주형 변수의 비교 검증에는 피어슨 카이제곱 검
증(Pearson's chi-square test)을 사용하였다. 각각의 삶의 질 영역에 독립적으로 연관된 요인들을 검증하기 위해 다중로 지스틱회귀분석(multiple logistic regression alaysis)을 사용 하였다. SPSS version 24(IBM Corp., Armonk, NY, USA)를 사용하여 통계 분석을 수행하였으며, 유의확률 $(p)$ 이 0.05 미 만일 경우 통계적으로 유의한 것으로 간주하였다.

\section{결 과}

총 2,501명이 설문조사에 응답하였다. 연령은 $47.9 \pm 16.4$ 세였고 여성은 1,259 명(50.3\%)이었다. 응답자의 성별 및 연 령 분포는 2018년 대한민국 19세 이상 인구의 분포와 유의한 차이가 없었다(Table 1). 중기 성인군은 모두 1,435명이었으 며 연령은 49.6 \pm 8.3세였고 여성은 728 명(50.7\%)이었으며,

Table 1. Demographic distribution of all survey participants and total population of Korea in 2018

\begin{tabular}{lrrr}
\hline & $\begin{array}{c}\text { Sample number, } \\
\mathrm{n}(\%)\end{array}$ & $\begin{array}{c}\text { Total population, } \\
\mathrm{n}(\%)\end{array}$ & $p^{*}$ \\
\hline $\begin{array}{l}\text { Sex } \\
\text { Female }\end{array}$ & $1,259(50.3)$ & $21,382,704(50.4)$ & 0.922 \\
$\quad$ Male & $1,242(49.7)$ & $21,011,341(49.6)$ & \\
Age (year) & & & 1.000 \\
$19-29$ & $434(17.4)$ & $7,361,167(17.4)$ & \\
$30-39$ & $425(17.0)$ & $7,207,282(17.0)$ & \\
$40-49$ & $498(19.9)$ & $8,422,806(19.9)$ & \\
$50-59$ & $498(19.9)$ & $8,487,313(20.0)$ & \\
$60-69$ & $345(13.8)$ & $5,794,293(13.7)$ & \\
$70-$ & $301(12.0)$ & $5,121,184(12.1)$ & \\
Total & $2,501(100)$ & $42,394,045(100)$ & \\
\hline
\end{tabular}

*compared sex and age group distributions between the sample of the study and total population of Korea in 2018

Table 2. Age, sleep quality, sleep quantity, chronotype, and quality of life variables according to chronotype and distinctiveness of circadian rhythm

\begin{tabular}{|c|c|c|c|c|c|c|}
\hline & \multicolumn{3}{|c|}{ Chronotype } & \multicolumn{3}{|c|}{ Distinctiveness } \\
\hline & Morningness & Eveningness & $p^{*}$ & Weak & Strong & $p^{\dagger}$ \\
\hline Number of participants & 351 & 167 & & 852 & 583 & \\
\hline Age (year) & $51.3 \pm 8.1$ & $47.7 \pm 8.2$ & $<0.001$ & $49.4 \pm 8.3$ & $49.9 \pm 8.2$ & 0.291 \\
\hline PSQI score & $3.6 \pm 2.2$ & $4.3 \pm 2.7$ & $<0.001$ & $3.6 \pm 2.5$ & $4.2 \pm 2.3$ & $<0.001$ \\
\hline Week average sleep duration (min) & $416.2 \pm 65.2$ & $423.1 \pm 68.1$ & 0.186 & $424.3 \pm 61.5$ & $424.4 \pm 67.4$ & 0.959 \\
\hline DI scale & $18.3 \pm 5.6$ & $19.0 \pm 4.9$ & 0.114 & NA & NA & NA \\
\hline ME scale & NA & NA & NA & $21.7 \pm 6.1$ & $21.8 \pm 7.7$ & 0.119 \\
\hline EQ-5D-3L utility score & $0.93 \pm 0.06$ & $0.93 \pm 0.07$ & 0.686 & $0.93 \pm 0.06$ & $0.93 \pm 0.06$ & 0.728 \\
\hline
\end{tabular}

Variables are presented as means \pm standard deviations. ${ }^{*}$ compared between morningness and eveningness, ${ }^{\dagger}$ compared between weak and strong distinctiveness of circadian rhythm. PSQI: Pittsburgh Sleep Quality Index, DI: distinctiveness, ME: morningness-eveningness, EQ-5D-3L: EuroQol-5D 3-level version, NA: not applicable 
성별에 따른 연령의 차이는 없었다.

\section{수면의 질과 양, 그리고 일주기리듬}

PSQI 총점 8.5점 이상으로 수면의 질이 불량한 사람은 69명 (4.8\%)이었고, 이 중 여성이 43 명(5.9\%)으로 남성의 26 명(3.7\%) 보다 높은 비율을 보였다 $(p=0.048)$ (Supplementary Table 1 in the online-only Data Supplement). PSQI 총점 또한 여성 에서 더 높았다( $4.0 \pm 2.6$ vs. $3.7 \pm 2.2, p=0.017$ ). 주간 평균 수 면시간은 $421.3 \pm 62.8$ 분이었으며 성별에 따른 차이는 없었 다 $(p=0.769)$. 일주기유형은 351 명 $(24.5 \%)$ 이 아침형이었고 301 명(21.0\%)이 저녁형이었으며, 583명(40.6\%)에서 일주기 리듬의 강한 분명성을 보였다. 저녁형이 아침형보다 평균 연 령이 낮았고(47.7 \pm 8.2 vs. $51.3 \pm 8.1, p<0.001) \mathrm{PSQI}$ 총점이 높았다(4.3 \pm 2.7 vs. $3.6 \pm 2.2, p<0.001$ (Table 2). 일주기리듬

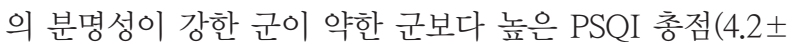
2.3 vs. $3.6 \pm 2.5, p<0.001)$ 을 보였으나 연령에는 차이가 없었 다. 주간 평균 수면시간은 일주기유형이나 일주기리듬에 분 명성에 따른 차이를 보이지 않았다(각각 $p=0.186,0.959$ ). $\mathrm{ME}$ 척도와 $\mathrm{DI}$ 척도 점수는 성별에 따른 차이를 보이지 않았 다(각각 $p=0.055,0.067$ ).

\section{삶의 질}

중기 성인의 $15.5 \%(223 / 1,435)$ 에서 통증/불편 부분의 장애 를 보고하였고, $11.4 \%(163 / 1,435)$ 에서 불안/우울을, $3.2 \%$ $(46 / 1,435)$ 에서 일상활동의 장애를, $3.1 \%(44 / 1,435)$ 에서 운동 능력의 장애를, $1.6 \%(23 / 1,435)$ 에서 자기 관리의 장애를 보고 하였다(Supplementary Table 1 in the online-only Data Supplement). EQ-5D-3L 총점은 일주기유형이나 일주기리듬의 분명성에 따른 차이를 보이지 않았다(각각 $p=0.686,0.728$ ). 삶의 질 5 개 영역 모두에서 장애 빈도의 성별에 따른 차이는 없었고(모든 영역에서 $p>0.08$ ), EQ-5D-3L 총점 또한 성별 에 따른 차이를 보이지 않았다.

\section{삶의 질과 수면의 질과 양, 일주기리듬의 연관성}

단변수 분석 결과 PSQI 총점은 삶의 질의 5 개 영역 모두에 서 장애 유무에 따라 차이를 보였다(Table 3). 연령은 운동능력 과 통증/불편 영역에서의 장애 유무에 따라 차이를 보였고, 주 간 평균 수면시간은 일상활동과 불안/우울 영역에서의 장애 유무에 따라 차이를 보였으며 DI 척도는 통증/불편과 불안/우 울 영역에서의 장애 유무에 따라 차이를 보였다. $\mathrm{ME}$ 척도는 삶의 질의 모든 영역에서 장애 유무에 따른 차이가 없었다.

다중로지스틱회귀분석 결과 불량한 수면의 질은 삶의 질 의 5 개 영역 모두에서 장애를 예측하는 독립적 요인이었다 
Table 4. Multiple logistic regression analysis for predicting impairments in 5 dimensions of EuroQol-5D

\begin{tabular}{|c|c|c|c|c|c|}
\hline & $\begin{array}{l}\text { Impaired mobility } \\
\text { OR }(95 \% \text { CI })\end{array}$ & $\begin{array}{l}\text { Impaired self-care } \\
\text { OR }(95 \% \mathrm{CI})\end{array}$ & $\begin{array}{c}\text { Impaired usual activities } \\
\text { OR }(95 \% \mathrm{CI})\end{array}$ & $\begin{array}{c}\text { Pain/discomfort } \\
\text { OR }(95 \% \mathrm{CI}) \\
\end{array}$ & $\begin{array}{c}\text { Anxiety/depression } \\
\text { OR (95\% CI) }\end{array}$ \\
\hline \multicolumn{6}{|l|}{ Age group } \\
\hline $35-44$ years & Ref. & Ref. & Ref. & Ref. & Ref. \\
\hline $45-54$ years & $0.985(0.406-2.388)$ & $1.851(0.557-6.147)$ & $1.321(0.575-3.033)$ & $1.186(0.809-1.740)$ & $0.873(0.565-1.348)$ \\
\hline $55-64$ years & $2.197(0.987-4.890)$ & $2.150(0.646-7.150)$ & $1.785(0.787-4.051)$ & $1.579(1.078-2.312)$ & $1.232(0.805-1.887)$ \\
\hline Poor sleep quality & $4.722(1.907-11.695)$ & $6.642(1.953-22.590)$ & $4.260(1.823-9.955)$ & $5.685(3.339-9.677)$ & $7.465(4.335-12.857)$ \\
\hline Sleep duration $<7 \mathrm{~h}$ & $0.852(0.447-1.627)$ & $0.394(0.147-1.053)$ & $1.505(0.798-2.836)$ & $0.765(0.562-1.041)$ & $1.063(0.748-1.511)$ \\
\hline \multicolumn{6}{|l|}{ Chronotype } \\
\hline Intermediate & Ref. & Ref. & Ref. & Ref. & Ref. \\
\hline Morningness & $1.161(0.560-2.407)$ & $1.028(0.350-3.019)$ & $1.319(0.658-2.645)$ & $1.039(0.727-1.484)$ & $0.932(0.619-1.401)$ \\
\hline Eveningness & $1.008(0.449-2.259)$ & $1.344(0.479-3.769)$ & $0.971(0.433-2.176)$ & $0.969(0.660-1.422)$ & $0.652(0.408-1.044)$ \\
\hline Strong distinctiveness & $1.395(0.752-2.589)$ & $1.389(0.591-3.265)$ & $1.517(0.829-2.777)$ & $1.589(1.182-2.136)$ & $1.412(1.003-1.987)$ \\
\hline
\end{tabular}

OR: odd ratio, CI: confidence interval, Ref.: reference

(Table 4). 일주기유형에 관한 요인 중에는 일주기유형의 강 한 분명성이 통증/불편[odd ratio(OR) $1.589,95 \%$ confidence interval(CI) 1.182 2.136]과 우울/불안(OR 1.412, 95\% CI 1.003 1.987)을 예측하는 독립적 요인이었다.

\section{고 찰}

본 연구는 중기 성인 인구에서 수면의 질, 수면의 양, 그리 고 일주기유형과 삶의 질의 연관성을 조사한 인구 기반 단면 연구이다. 수면의 질은 삶의 질에 가장 강한 영향을 미치는 인자였다. 시간적 선호도로 표현되는 일주기유형 자체는 삶 의 질에 유의한 영향을 보이지 않았으나, 일주기리듬의 분명 성은 삶의 질 중 통증이나 불편, 그리고 불안이나 우울에 영 향을 미치는 독립적 인자였다.

본 연구에서 대한민국 중기 성인 인구의 $\mathrm{PSQI}$ 총점은 평 균 3.9점이었으며, 모집단인 성인 전체의 평균(3.8점)과 유사 한 숫자였다. 이는 독일의 인구 60 만 명 규모의 도시에서의 인구 기반 조사(18 80세)에서의 5.0 점 ${ }^{10}$ 이나 오스트리아의 인구기반 조사(15세 이상)에서의 4.6점, ${ }^{12}$ 홍콩 인구 기반 조 사(18세 이상)에서의 5.3점, ${ }^{11}$ 그리고 중국 후난성의 인구 기 반 조사(12세 이상)에서의 4.3점 22 보다 낮은 수치이다. 실제 한국인에서 수면의 질이 다른 몇 나라보다 높을 수도 있으 나, 문화적 차이로 인해 수면의 질에 대한 주관적인 평가가 다를 수 있으며, 언어적인 차이가 이러한 차이에 기여한 것 일 수도 있다. 여성이 남성보다 수면의 질이 낮다는 점은 이 전의 연구들과 공통적인 현상이다. ${ }^{10-12,23}$

중기 성인에서 수면의 질은 연령이나 다른 수면 관련 인자 들보다 삶의 질과 강한 연관성을 보였다. 수면의 질과 삶의 질 에 대한 연관성은 여러 연구에서 제시된 바 있다. 본 연구와
같은 인구 기반 연구 중에서는 전체 성인을 포함하는 오스트 리아와 독일의 연구, ${ }^{10,12}$ 중국의 $18 \sim 55$ 세,${ }^{24}$ 미국의 20 39세,${ }^{25}$ 리투아니아의 35 74세 ${ }^{26}$ 를 대상으로 한 연구 등 여러 국가의 인구 기반 연구에서 수면의 질은 삶의 질과 강한 연관성을 보인다. 대학생을 대상으로 한 연구나 노인을 대상으로 한 연구에서도 수면의 질과 삶의 질 사이의 연관성을 보고하고 있다. ${ }^{27-30}$

성인의 일주기유형과 삶의 질에 대한 연구는 대체로 저녁 형과 낮은 삶의 질의 연관성을 보여왔다. 40 69세의 안산 시 민 2,976명으로 구성된 코호트 연구 결과 저녁형에서 흡연과 취침 전 음주, 수면, 강한 운동 등 수면에 방해되는 행동이 빈 번하며 수면 장애가 흔하고, 신체활동이 적으며 삶의 질이 낮았다. ${ }^{31}$ 저녁형의 낮은 삶의 질과의 연관성은 아침 일찍 출 근해야 하는 사람에게서 더욱 뚜렷하였다. ${ }^{15}$ 이는 저녁형 일 주기유형에서 사회적 시간과의 불일치로 인한 수면시간의 감 소가 낮은 삶의 질과의 연관성에 역할을 함을 시사한다. 19세 이상 성인을 대상으로 한 단면연구에서, 늦은 일주기유형의 사람들과 수면시간이 짧은 사람들에서 주말에 수면을 보충하 는 경우에 그렇지 않은 사람에 비해 삶의 질이 높았다. ${ }^{13}$ 본 연구의 중기 성인에서는 저녁형이 아침형에 비해 수면의 질 이 낮았으나 삶의 질은 아침형과 비교하여 뚜렷한 차이를 보 이지 않았는데, 이는 저녁형과 아침형 두 군 간의 주간 평균 수면시간에 차이가 없었기 때문일 수 있으며, 수면시간 부족 이 저녁형과 낮은 삶을 연관 짓는 주된 인자라는 이전 연구 의 결과들을 뒷받침하는 것으로 보인다. ${ }^{13,15}$

그간 흔히 사용되어 온 Horne과 Östberg의 MorningnessEveningness Questionnaire를 비롯한 일주기유형 측정 도구 들은 일주기리듬의 위상을 측정하여 아침형과 저녁형을 구분 하는 것에 초점을 맞추고 있다. ${ }^{32-36}$ 그러나 동일하게 오전 6시 
기상을 선호하는 아침형의 사람이라도 오후 10 시가 되면 눈 을 뜨고 있을 수 없는 정도로 졸림을 느끼는, 즉 일주기리듬 의 분명성이 강한 사람은 오후 10 시에도 충분히 업무에 집중 할 수 있는 사람보더 더 강한 아침형이라 볼 수 있다. ${ }^{17}$ 일주기 리듬의 선호도가 사회적 시간과 다르더라도 이러한 불일치 에 잘 적응하는 경우와 그렇지 않은 경우에서 삶의 질에 대 한 영향이 다를 것을 추정할 수 있다. 저자들이 아는 한도 내 에서는 일주기리듬의 분명성과 삶의 질의 연관성을 분석한 연구는 아직 없다. 본 연구 결과는 일주기리듬에서 리듬의 분 명성이 위상보다 삶의 질에 더 중요한 인자임을 시사한다. Laborde 등은 일주기리듬의 강한 분명성과 저녁형 일주기유 형이 긍정적 성격의 지표와 음의 연관성을 가짐을 보고하여 분명성 또한 위상만큼 중요한 인자임을 시사한다. ${ }^{37}$ 게다가 계절성 기분장애는 일주기리듬의 위상보다는 일주기리듬의 분명성과 연관된다. ${ }^{38}$ 일주기리듬의 분명성이 강한 환자에서 삶의 질에 상당한 영향을 미치는 기분장애와 불안장애의 위 험이 높다는 것은 본 연구와 일치하는 결과이다. ${ }^{39}$

일주기유형이 연령에 따라 변한다는 것은 잘 알려져 있 다. ${ }^{4-6}$ 본 연구의 중기 성인에서도 저녁형은 아침형보다 평균 연령이 낮았다. 그러나 일주기리듬의 분명성이 강한 군과 약 한 군의 평균연령에는 차이가 없었다. 이는 일주기리듬의 분 명성이 일주기의 시간적 선호도보다 개인에게 나이에 따른 변화 없이 안정적으로 유지되는 성향임을 시사한다.

본 연구에는 다음과 같은 한계점이 있다. 첫째로, 객관적 인 측청 도구가 아닌 주관적인 설문 도구를 통해 얻은 데이 터를 기반으로 하였다. 기억의 왜곡, 응답의 진실성 등이 결 과를 편향시킬 가능성을 배제할 수 없다. 그러나 표준화된 설문 도구를 사용하였고, 교육받은 조사자가 대면조사를 시 행함으로써 이러한 한계를 최소화하고자 하였다. 두 번째는 단면연구의 한계로, 본 연구에서 수면의 질과 양, 일주기유 형, 그리고 삶의 질 사이의 연관성을 확인할 뿐 인과관계를 추론할 수는 없다.

그러나 본 연구는 전체 인구를 대표하는 비교적 대규모 표 본을 대상으로 한 연구로서, 낮은 수면의 질, 그리고 강한 일 주기리듬의 낮은 삶의 질과의 연관성과 그 정도를 비교적 정 확하게 추정할 수 있다. 향후 일주기유형과 관련한 연구뿐 아니라 일주기리듬의 장애를 가진 환자의 진료에 있어서도 일주기리듬의 위상에 더불어 리듬의 분명성이 고려되어야 할 것이다.

\section{Supplementary Materials}

The online-only Data Supplement is available with this article at https:// doi.org/10.13078/jsm.200005.

\section{Acknowledgments}

This study was supported by the Research Grant of Korean Sleep Research Society in 2018.

\section{Conflicts of Interest}

The authors have no potential conflicts of interest to disclose.

\section{ORCID iDs}

$\begin{array}{ll}\text { Daeyoung Kim } & \text { https://orcid.org/0000-0001-9056-0017 } \\ \text { Hee Jin Chang } & \text { https://orcid.org/0000-0002-0584-6940 } \\ \text { Wankiun Lee } & \text { https://orcid.org/0000-0003-3413-9935 } \\ \text { Hoseong Seo } & \text { https://orcid.org/0000-0002-2388-8132 } \\ \text { Kwang Ik Yang } & \text { https://orcid.org/0000-0001-6343-6520 } \\ \text { Min Kyung Chu } & \text { https://orcid.org/0000-0001-6221-1346 } \\ \text { Chang-Ho Yun } & \text { https://orcid.org/0000-0003-2204-8067 }\end{array}$

\section{Author Contributions}

Conceptualization: Min Kyung Chu, Kwang Ik Yang, Chang-Ho Yun, Daeyoung Kim. Data curation: Min Kyung Chu, Kwang Ik Yang, Chang-Ho Yun, Daeyoung Kim. Formal analysis: Daeyoung Kim. Methodology: Min Kyung Chu, Kwang Ik Yang, Chang-Ho Yun, Daeyoung Kim. Writingoriginal draft: Daeyoung Kim. Writing_-review \& editing: all authors.

\section{REFERENCES}

1. Adan A, Archer SN, Hidalgo MP, Di Milia L, Natale V, Randler C. Circadian typology: a comprehensive review. Chronobiol Int 2012;29: 1153-1175.

2. Tankova I, Adan A, Buela-Casal G. Circadian typology and individual differences. A review. Pers Individ Dif 1994;16:671-684.

3. Cavallera GM, Giudici S. Morningness and eveningness personality: a survey in literature from 1995 up till 2006. Pers Individ Dif 2008;44:3-21.

4. Carrier J, Monk TH, Buysse DJ, Kupfer DJ. Sleep and morningnesseveningness in the 'middle' years of life (20-59 y). J Sleep Res 1997;6: 230-237.

5. Paine SJ, Gander PH, Travier N. The epidemiology of morningness/ eveningness: influence of age, gender, ethnicity, and socioeconomic factors in adults (30-49 years). J Biol Rhythms 2006;21:68-76.

6. Randler C, Bilger S. Associations among sleep, chronotype, parental monitoring, and pubertal development among German adolescents. $J$ Psychol 2009;143:509-520.

7. Roenneberg T, Kuehnle T, Pramstaller PP, et al. A marker for the end of adolescence. Curr Biol 2004;14:R1038-R1039.

8. Adan A, Natale V. Gender differences in morningness-eveningness preference. Chronobiol Int 2002;19:709-720.

9. Duarte LL, Menna-Barreto L, Miguel MA, et al. Chronotype ontogeny related to gender. Braz J Med Biol Res 2014;47:316-320.

10. Hinz A, Glaesmer H, Brähler E, et al. Sleep quality in the general population: psychometric properties of the Pittsburgh Sleep Quality Index, derived from a German community sample of 9284 people. Sleep Med 2017;30:57-63.

11. Wong WS, Fielding R. Prevalence of insomnia among Chinese adults in Hong Kong: a population-based study. J Sleep Res 2011;20:117-126.

12. Zeitlhofer J, Schmeiser-Rieder A, Tribl G, et al. Sleep and quality of life in the Austrian population. Acta Neurol Scand 2000;102:249-257.

13. Oh YH, Kim H, Kong M, Oh B, Moon JH. Association between weekend catch-up sleep and health-related quality of life of Korean adults. Medicine (Baltimore) 2019;98:e14966.

14. Roeser K, Brückner D, Schwerdtle B, Schlarb AA, Kübler A. Healthrelated quality of life in adolescent chronotypes-A model for the effects of sleep problems, sleep-related cognitions, and self-efficacy. Chronobiol Int 2012;29:1358-1365.

15. Sasawaki Y, Shiotani H. The influence of chronotype and working 
condition on sleep status and health related quality of life of daytime office workers. Kobe J Med Sci 2019;64:E189-E196.

16. Statistics Korea. 2018 population and housing census. SGIS. [cited 2020 Feb 16]. URL:https://sgis.kostat.go.kr/view/map/interactiveMap/populationHouseView.

17. Ogińska H. Can you feel the rhythm? A short questionnaire to describe two dimensions of chronotype. Pers Individ Dif 2011;50:1039-1043.

18. Buysse DJ, Reynolds CF 3rd, Monk TH, Berman SR, Kupfer DJ. The Pittsburgh Sleep Quality Index: a new instrument for psychiatric practice and research. Psychiatry Res 1989;28:193-213.

19. Sohn SI, Kim DH, Lee MY, Cho YW. The reliability and validity of the Korean version of the Pittsburgh Sleep Quality Index. Sleep Breath 2012;16:803-812.

20. EuroQol Group. EuroQol--A new facility for the measurement of healthrelated quality of life. Health Policy 1990;16:199-208.

21. Lee YK, Nam HS, Chuang LH, et al. South Korean time trade-off values for EQ-5D health states: modeling with observed values for 101 health states. Value Health 2009;12:1187-1193.

22. Tang J, Liao Y, Kelly BC, et al. Gender and regional differences in sleep quality and insomnia: a general population-based study in Hunan province of China. Sci Rep 2017;7:43690.

23. Schredl M, Schenck W, Görtelmeyer R, Heuser I. Einflußfaktoren auf die Schlafqualität bei Gesunden. Somnologie (Berl) 1998;2:99-103.

24. Zhou M, Chen M, Feng P, et al. [Partial canonical correlation analysis on the association between quality of sleep and quality of life among residents in Suzhou city]. Zhonghua Liu Xing Bing Xue Za Zhi 2012;33: 1040-1043.

25. Chen X, Gelaye B, Williams MA. Sleep characteristics and health-related quality of life among a national sample of American young adults: assessment of possible health disparities. Qual Life Res 2014;23:613-625.

26. Andruskiene J, Varoneckas G, Martinkenas A, Grabauskas V. Factors associated with poor sleep and health-related quality of life. Medicina (Kaunas) 2008;44:240-246.

27. Pilcher JJ, Ginter DR, Sadowsky B. Sleep quality versus sleep quantity: relationships between sleep and measures of health, well-being and sleepiness in college students. J Psychosom Res 1997;42:583-596.

28. Buboltz Jr. W, Jenkins SM, Soper B, Woller K, Johnson P, Faes T. Sleep habits and patterns of college students: an expanded study. J Coll Couns 2009;12:113-124.

29. Tel H. Sleep quality and quality of life among the elderly people. Neurol Psychiatry Brain Res 2013;19:48-52.

30. Marques DR, Meia-Via AMS, da Silva CF, Gomes AA. Associations between sleep quality and domains of quality of life in a non-clinical sample: results from higher education students. Sleep Health 2017;3:348-356.

31. Suh S, Yang HC, Kim N, et al. Chronotype differences in health behaviors and health-related quality of life: a population-based study among aged and older adults. Behav Sleep Med 2017;15:361-376.

32. Horne JA, Östberg O. A self-assessment questionnaire to determine morningness-eveningness in human circadian rhythms. Int J Chronobiol 1976;4:97-110.

33. Smith CS, Reilly C, Midkiff K. Evaluation of three circadian rhythm questionnaires with suggestions for an improved measure of morningness. J Appl Psychol 1989;74:728-738.

34. Carskadon MA, Vieira C, Acebo C. Association between puberty and delayed phase preference. Sleep 1993;16:258-262.

35. Smith CS, Folkard S, Schmieder RA, et al. Investigation of morningevening orientation in six countries using the preferences scale. Pers Individ Dif 2002;32:949-968.

36. Roenneberg T, Wirz-Justice A, Merrow M. Life between clocks: daily temporal patterns of human chronotypes. J Biol Rhythms 2003;18:80-90.

37. Laborde S, Guillén F, Dosseville F, Allen MS. Chronotype, sport participation, and positive personality-trait-like individual differences. Chronobiol Int 2015;32:942-951.

38. Oginska H, Oginska-Bruchal K. Chronotype and personality factors of predisposition to seasonal affective disorder. Chronobiol Int 2014; 31:523-531.

39. Nowakowska-Domagała K, Mokros Ł, Jabłkowska-Górecka K, Grzelińska J, Pietras T. The relationship between chronotype and personality among patients with alcohol dependence syndrome: pilot study. Chronobiol Int 2016;33:1351-1358. 
Supplementary Table 1. Age, sleep quality, sleep quantity, chronotype, and quality of life variables of middle adult (35 years or older and younger than 65 years) participants

\begin{tabular}{|c|c|c|c|c|}
\hline & All sex & Female & Male & $p^{*}$ \\
\hline Number or participants & $1,435(100)$ & $728(100)$ & $707(100)$ & \\
\hline Age (year) & $49.6 \pm 8.3$ & $49.7 \pm 8.3$ & $49.5 \pm 8.2$ & 0.586 \\
\hline PSQI score & $3.9 \pm 0.1$ & $4.0 \pm 2.6$ & $3.7 \pm 2.2$ & 0.017 \\
\hline Poor sleep quality & $69(4.8)$ & $43(5.9)$ & $26(3.7)$ & 0.048 \\
\hline Week average sleep duration (min) & $421.3 \pm 62.8$ & $422.6 \pm 61.3$ & $423.3 \pm 61.7$ & 0.769 \\
\hline ME scale & $21.7 \pm 0.2$ & $22.1 \pm 6.9$ & $21.4 \pm 6.7$ & 0.055 \\
\hline Morningness & $351(24.5)$ & $167(22.9)$ & $184(26.0)$ & 0.152 \\
\hline Eveningness & $301(21.0)$ & $166(22.8)$ & $135(19.1)$ & 0.152 \\
\hline DI scale & $18.0 \pm 0.1$ & $18.3 \pm 4.9$ & $17.8 \pm 5.0$ & 0.067 \\
\hline Strong distinctiveness & $583(40.6)$ & $306(42.0)$ & $277(39.2)$ & 0.271 \\
\hline EQ-5D-3L utility score & $0.931 \pm 0.061$ & $0.929 \pm 0.061$ & $0.933 \pm 0.062$ & 0.265 \\
\hline \multicolumn{5}{|l|}{ Quality of life } \\
\hline Impaired mobility & $44(3.1)$ & $22(3.0)$ & $22(3.1)$ & 0.921 \\
\hline Impaired self-care & $23(1.6)$ & $9(1.2)$ & $14(2.0)$ & 0.262 \\
\hline Impaired usual activities & $46(3.2)$ & $23(3.2)$ & $23(3.3)$ & 0.920 \\
\hline Pain/discomfort & $223(15.5)$ & $120(16.5)$ & $103(14.6)$ & 0.317 \\
\hline Anxiety/depression & $163(11.4)$ & $93(12.8)$ & $70(9.9)$ & 0.086 \\
\hline
\end{tabular}

Variables are presented as means \pm standard deviations or numbers (percentage). * compared between genders. PSQI: Pittsburgh Sleep Quality Index, ME: morningness-eveningness, DI: distinctiveness, EQ-5D-3L: EuroQol-5D 3-level version 